Proc. Indian Acad. Sci. (Earth Planet. Sci.), Vol. 90, Number 1, March 1981, pp. 55-62.

(C) Printed in India.

\title{
Daily variation of geomagnetic field at low latitudes associated with stable solar wind flow
}

\author{
G K RANGARAJAN \\ Indian Institute of Geomagnetism, Colaba, Bombay 400 005, India
}

MS received 15 September 1980; revised 18 Docember 1980

\begin{abstract}
Mean diurnal variation of $\boldsymbol{H}$ at low and oquatorial latitudes is computod for days in the vicinity of passage of "quiet" solar wind. It is shown that the prepassage magnitude of the diurnal variation is appreciably larger when compared to post-passage intervals at low latitudes but the difference vanishes in the electrojet region. It is suggested that the $\mathrm{Sq}$ current system moves towards dip equator immediately following quiet wind conditions relative to oarliar periods. It is also shown that during conditions of stable solar wind, the solar wind proton density is inversely rolated to the eloctrojet strength, while at low latitudos outside the jot influence, there is no clear association.
\end{abstract}

Keymords. Quiet solar wind; equatorial magnetic field: proton donsity; geo magnetic field; low latitudes.

\section{Introduction}

In situ measurements of solar wind by spacecraft have shown that the parameters characterizing the solar wind are highly variable. However it is possible to identify intervals of time during which speed, donsity, etc., romain constant to within specified limits. Prigancova (1978) identified quiet intervals of solar wind from extensive observations in space of solar wind velocity. Days with noticeable variation in density and thermal velocity of protons were eliminated. Earlier, Neugebauer (1976) also identified duration of quiet solar wind with the stipulation that speed, density and temperature variations are small over periods comparable to the time taken for the solar wind from the sun to reach the earth. Despite the slightly different approaches, all the eleven intervals of Prigancova (1978). are included in the list of Neugebauer (1976) who could identify 3 more intervals.

In this paper we show that the duration of such stable solar wind sweeping past the earth is marked by different characteristics of the daily variation at low latitude stations, before and after the passage whereas within the electrojet region the difference vanishes. We also show that during conditions of stable solar wind, proton density is inversely correlated with the diurnal range close to the dip equator but at low latitudes the correlation vanishes, and tends to reverso close to Sq focus. 


\section{Data analysis}

We have utilized the list of 11 intervals between 1965 and 1972 given by Prigancova (1978) and the mean hourly values of the horizontal component derived from the magnetograms of six Indian stations corrocted for non-cyclic change and secular trend. The co-ordinates of the stations are given in table 1. Three of these stations are in the equatorial electrojet region and three others are located outside the jet influence. Sabhawala is close to the focal latitude of the equivalent $\mathrm{Sq}$ current system in the northern hemisphere.

The average diurnal variation for 6 days, beginning with 2 days prior to the onset of the stable solar wind conditions at each of the stations, has been computed, together with the standard errors associated with mean hourly value. The mean duration of the stable solar wind conditions derived from the eleven samples is about 50 bours so that $(0)$ and $(+1)$ can be considered to be days of stable solar wind intervals, $(-1)$ may be considered representative of conditions before the beginning and $(+2)$ that following the termination of the passage of stable wind.

\section{Results and discussion}

\subsection{Diurnal variation of the magnetic field}

The average diurnal variation for two representative stations for the four days categorized as above is shown in figure 1. All the three electrojet stations have similar features as shown for Trivandrum and the variation at non-electrojet stations is similar to that shown for Hyderabad. It is immediately clear that irrespective of the conditions of solar wind in the vicinity of a stable structure, the diurnal variation (both form and magnitude) in the equatorial magnetic field is almost the same. On the other hand, the mean diurnal variarion on day $(-1)$

Table 1. List of stations and thoir coortinatos.

\begin{tabular}{llcccc}
\hline & Station & \multicolumn{2}{c}{ Geographic } & \multicolumn{2}{c}{ Dipole } \\
\hline Name & Code & Lat. & Long. & Lat. & Long. \\
\hline Trivandrum & TRD & $8^{\circ} 29^{\prime} \mathrm{N}$ & $76^{\circ} 57^{\prime} \mathrm{E}$ & $1^{\circ} \cdot 2 \mathrm{~S}$ & $146^{\circ} \cdot 4$ \\
Kodaikanal & KOD & $10^{\circ} 14^{\prime} \mathrm{N}$ & $77^{\circ} 28^{\prime} \mathrm{E}$ & $0^{\circ} \cdot 6 \mathrm{~N}$ & $147^{\circ} \cdot 1$ \\
Annamalainagar & ANN & $11^{\circ} 22^{\prime} \mathrm{N}$ & $79^{\circ} 41^{\prime} \mathrm{E}$ & $1^{\circ} \cdot 4 \mathrm{~N}$ & $149^{\circ} \cdot 4$ \\
Hyderabad & $\mathrm{HYB}$ & $17^{\circ} 25^{\prime} \mathrm{N}$ & $78^{\circ} 33^{\prime} \mathrm{B}$ & $7^{\circ} \cdot 6 \mathrm{~N}$ & $148^{\circ} \cdot 9$ \\
Alibag & $\mathrm{ABG}$ & $18^{\circ} 38^{\prime} \mathrm{N}$ & $72^{\circ} 52^{\prime} \mathrm{E}$ & $9^{\circ} \cdot 5 \mathrm{~N}$ & $143^{\circ} \cdot 6$ \\
Sabhawala & $\mathrm{SAB}$ & $30^{\circ} 22^{\prime} \mathrm{N}$ & $77^{\circ} 48^{\prime} \mathrm{E}$ & $20^{\circ} \cdot 8 \mathrm{~N}$ & $149^{\circ} \cdot 8$ \\
\hline
\end{tabular}




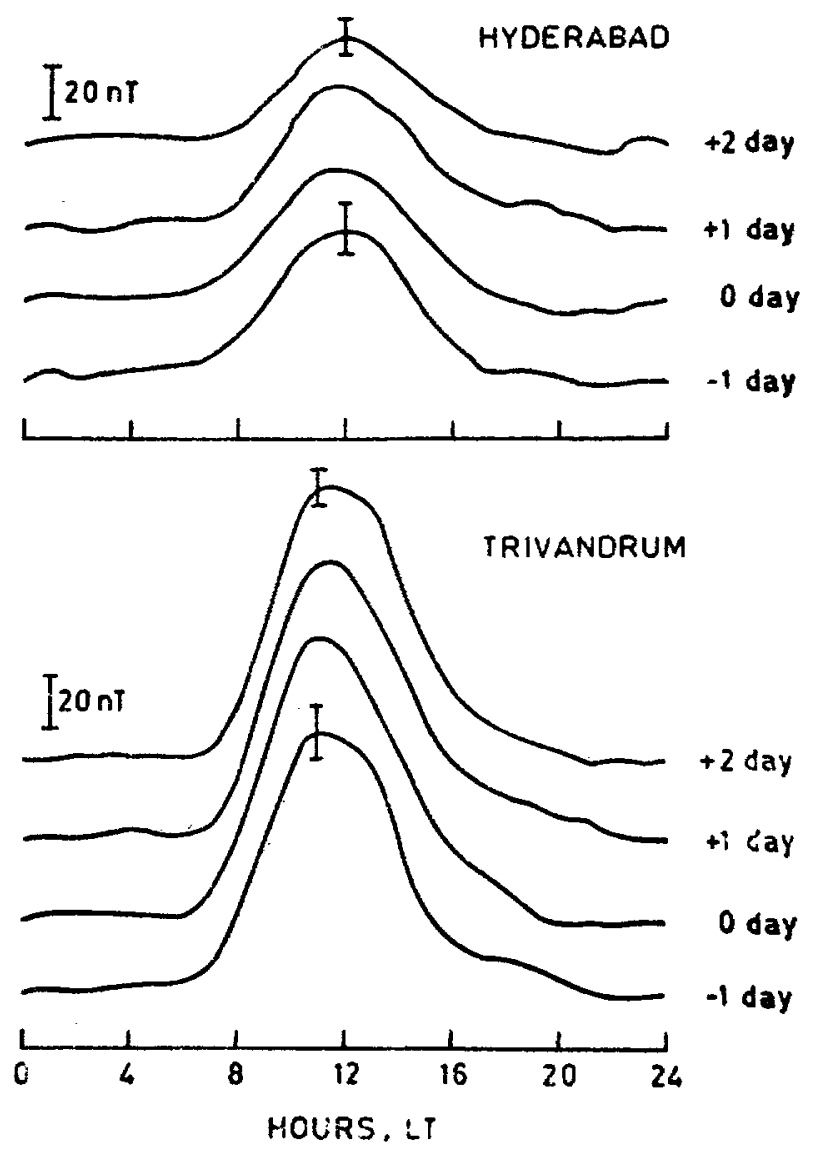

Figare 1. Mean diurnal variation of $H$ at Trivandrum and Hyderabad derived from 11 days observations in the vicinity of stable solar wind conditions. The curves have been shifted by equal spacing to avoid overlap.

for the low latitudo stations Hyderabad, Alibag and Sabhawala is significantly different from that on $(+2)$ day with other two days falling in between. The range of Sq $(H)$ for pre-passage, post-passage and during passage of stable wind for Trivandrum is 100,103 and $105 \mathrm{nT}$ respectively while at Hyderabad the corresponding range is 59,37 and 50 respectively. To bring out this feature more clearly, we have shown in figure 2 the difference in the mean hourly values on $(-1)$ day and $(+2)$ day for all the six stations. Standard errors for the differences in the mean hourly values at some points are also shown. It is clear that the differences are significant for daylight hours centred on local noon at nonelectrojet stations. The variation curve suggests that at low latitudes the Sq current strength is diminished following stable solar wind conditions. The modifications, if any, brought about by the passage of stable wind conditions on the equatorial electrojet strength is not as clearly evident. The difference curve for the three equatorial stations are semidiurnal in nature with minimum after loon 


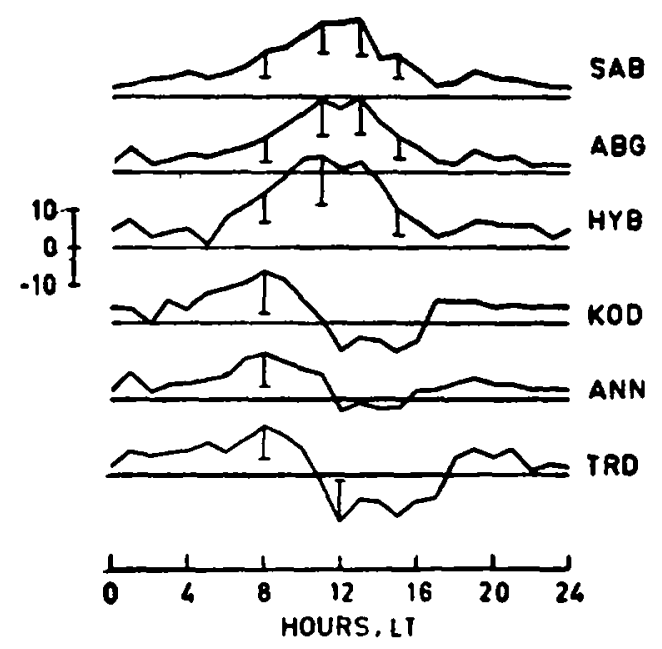

Figure 2. Diurnal variation in the difference of mean hourly values on $(-1)$ day and $(+2)$ day at six Indian stations.

noon and two maxima at 08 and 20 LT. This feature of the daily variation is most pronounced at Trivandrum close to the centre of the electrojet as compared to the station like Annamalainagar on the fringe of the electrojet belt. Reduction in the range of diurnal variation in $H$ at low latitudes could be brought about by reduced $\mathrm{Sq}$ current strength and/or equatorward shift of the focus of the current system. Kane (1974) pointed out that for studying changes of Sq current strength, $H$ variations may be a poor indicator as the focal latitude also changes from day to day. Instead, the $Y$ component ( $H \sin D$, where $D$ is the declination) would be a more satisfactory indicator of the strength. We utilized the $Y$-variations at Sabhawala and Alibag for the 11 intervals and found that the diurnal characteristics on $(-1)$ and $(+2)$ days did not differ significantly. This suggests that equatorward movement of the $\mathrm{Sq}$ current system on the day following termination of stable solar wind conditions is mainly responsible for the reduced $H$ variations at low latitudes. The absence of appreciable difference between these two days at stations close to dip equator is in conformity with this conclusion as the electrojet strength enhances when Sq current system moves towards equator (Tarpley 1973) thereby off-settting the reduction in the field due to diminished Sq currents.

\subsection{Day-to-day variability in the magnetic field at low latitudes}

A feature of interest in the calculation of standard error for the mean hourly value for each day based on the data of 11 chosen intervals was that the variability associated with the mean on day $(-1)$ was larger than on other days.

Local time dependence of day-to-day variability in $H$ at Alibag has been studied in detail by Bhargava and Yacob (1974) and Yacob and Arora (1974). While the first authors utilized data for all days (including disturbed days), the latter confined 
their analysis to quiet days only. Bhargava and Yacob (1974) found that variability was consistently small between 04 and 05 LT and peaked at the time of maximum of $\mathrm{Sq}(H)$. For quiet days also the peak variability was near the time of $\mathrm{Sq}(H)$ maximum but the variance was substantially reduced between midnight and dawn without a well-defined minimum.

To check whether the diurnal features of variability exhibit any noticeable dependence on the solar wind conditions, the hour-to-hour change in standard error for the four days $(-1,0,+1$ and +2$)$ are graphed, for a typical station Hyderabad in figure 3 . The nature of the diurnal variation for any given day was similar at all the six stations. The most striking feature of the variability apart from the maximum near local noon on all the four days, is the reduced magnitude on +1 day in comparison to -1 day. In other words, the day of least variability is not the same as the day of reduced $\mathrm{Sq}(H)$ range which occurs a day later. Another interesting aspect of the variability on $(+1)$ day is the shift in the peak towards earlier part of the day. These results show that apart from the dominant contribution from Sq currents to the day-to-day variability, solar wind narameters also control the nature of variability of the $\mathrm{Sq}(H)$ at low latitudes and that during conditions of stable solar wind, the variability is less.

\subsection{Stable solar wind and global geomagnetic activity}

In view of the fact that characteristics of solar wind play such a crucial part in controlling the diurnal variation at low and equatorial latitudes, it would be informative to study if the features are global. For this purpose, the mean daily

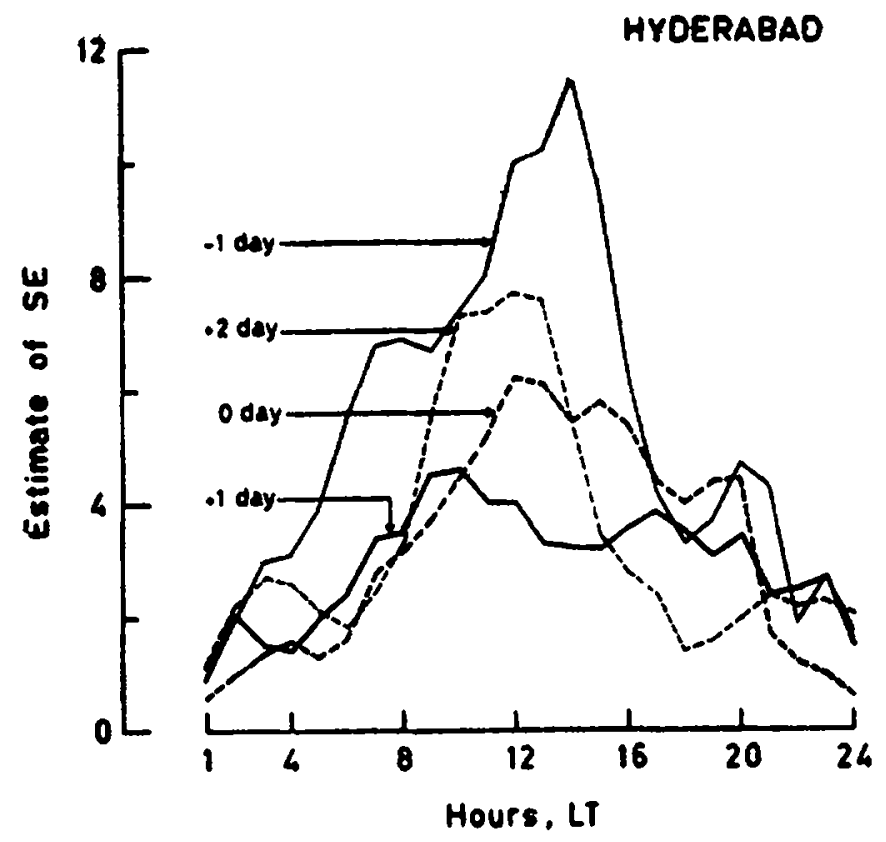

Figure 3. Diurnal variation in day-to-day variability of the field in the vicinity of stable solar wind conditions. Days $(0)$ and $(+1)$ correspond to stable wind intervals, $(-1)$ day precedes and $(+2)$ day follows the stable wind conditions. The ordinate is single standard error estimated from the hourly values for 11 days. 
index Ap of geomagnetic activity and equatorial Dst index (least hourly value for each day) were also averaged for the same 11 days. The variation of Ap and Dst between -2 and +3 days are shown in figure 4. Both $A p$ and negative Dst have largest magnitudes on $(-1)$ day and least on $(+2)$ day in the vicinity of stable solar wind conditions. As Ap represents geomagnetic activity which is controlled predominantly by magnetospheric substorms and Dst represents predominantly the intensity of the equatorial ring current, it may be inferred that contributions from solar wind parameters to magnetospheric tail (controlling substorm activity) and "equatorial ring current (controlling low latitude field changes) are reduced in the immediate post-passage intervals of stable solar wind intervals. It may be mentioned that of the 66 days considered for analysis only 2 days on (-2) day, 2 on $(-1)$ day and 1 on (0) day were classified as international disturbed (ID) days; therefore the $\mathrm{Sq}(H)$ pattern derived earlier may not be vitiated by large-scale global disturbances.

\subsection{Parameters of stable solar wind and equatorial magnetic field}

The list of quiet solar wind intervals identified by Neugebauer (1976) was derived from several spacecrafts. To avoid the substantial difference that can arise between different instruments especially in regard to calibration of density measurements, she adopted a normalization procedure with Explorer 35 as the standard. While the IMF magnitude was found to be nearly constant, the normalized solar wind parameters, bulk speed $(V)$, thermal speed $(W)$ and proton density $(N)$ were not constant for the different intervals.

In view of our earlier result that the difference in response to intervals preceding and succeeding quiet solar wind is appreciable at low latitudes but absent near the dip equator, it would be interesting to find out whether during the conditions of stable solar wind the fields at low latitude and in the jet region exhibit different characteristics. For this purpose we have utilized the mean diurnal range $R$ (maximum-minimum hourly values) averaged for days 0 and 1 . Linear regression analysis between range for each of the six stations and the three solar wind

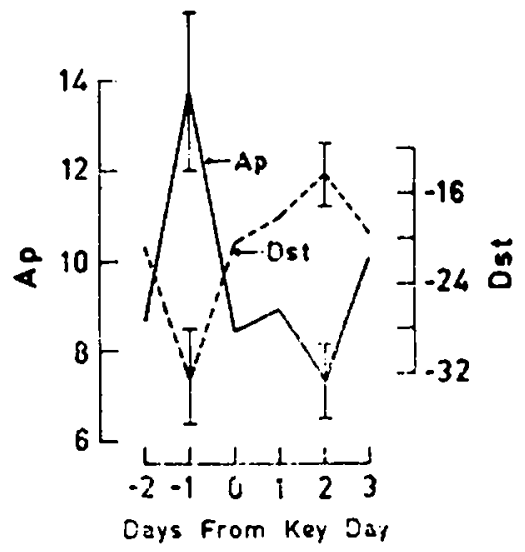

Figure 4. The variation in the planetary $A p$ index and equatorial Dst index for six days in the vicinity of stable solar wind conditions. 


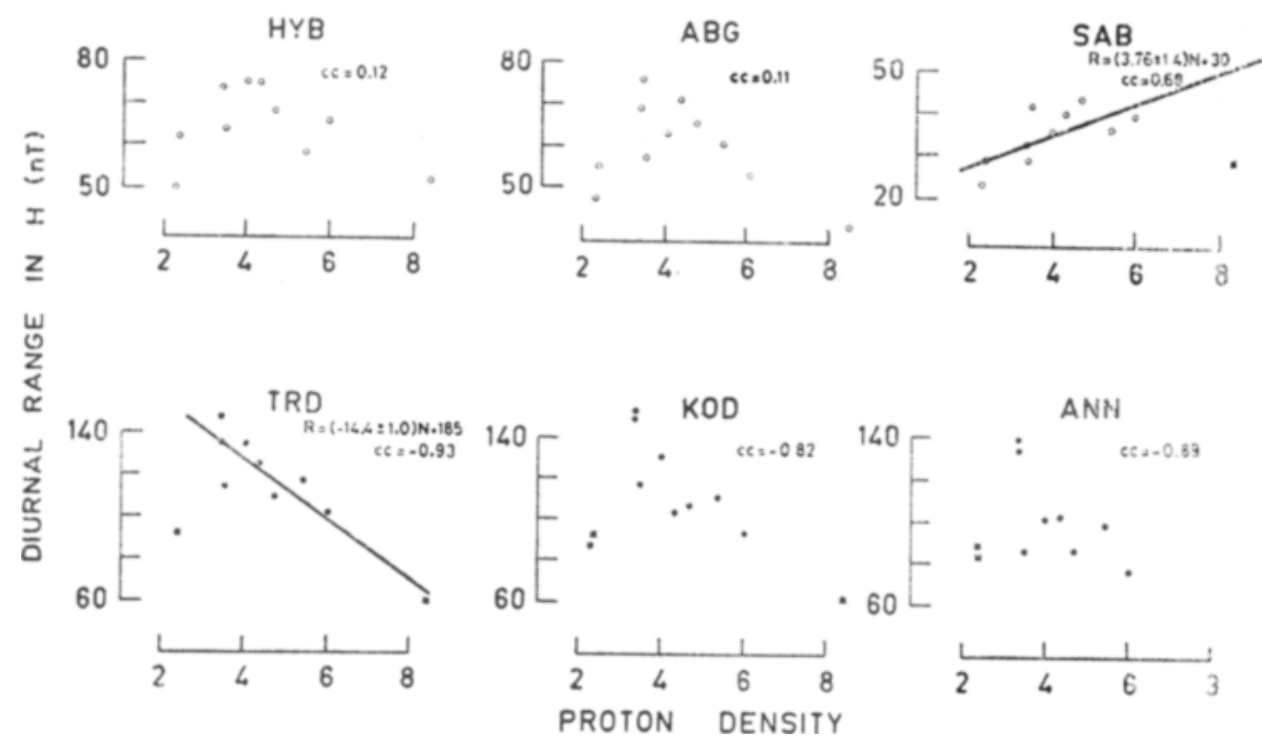

Figure 5. Scatter plot between proton density $(N)$ in stable solar wind and the diumal range $(R)$ in $H$ [mean of $(0)$ and $(+1)$ days] at six Indian stations. The line of best fit for Trivandrum and Sabhawala are also indicated.

parameters $N, V$ and $W$ were carried out. We find that at equatorial latitudes proton number density $(N)$ is inversely correlated with the diurnal range. $R$ does. not show any significant linear dependence on velocity $(V)$ or thermal speed $(W)$ $R$ at low latitudes is not significantly correlated with any of the three parameters. The scatter plots of number density and the range are shown in figure 5 . In the electrojet region when the two points corresponding to lowest density values are not included the inverse linear relationship becomes quite significant. The correlation coefficient (CC) increases from nearly -0.5 to -0.9 . On the other hand ranges at Hyderabad and Alibag fail to show any dependence on the number density even if one eliminates either the lowest or highest values. The tendency, if any, at Sabhawala near the $\mathrm{Sq}$ focus seems to be reversed, i.e., an increase in range with increased $N$, when the highest value of proton density is not taken into consideration. The corresponding correlation coefficient increases to 0.68 .

It, therefore, appears that under conditions of quiet solar wind, equatorial electrojet strength gets reduced when the proton density in solar wind increases. At low latitudes the effect is not noticeable. Closer to the Sq focus, there appears to be a reversal in this tendency. The mechanism responsible for these associations is not clear. Further study using proton density, solar wind velocity and low latitude $\mathrm{Sq}(H)$ is expected to give a clear picture of the interaction between stable solar wind and equatorial geomagnetic field. 


\section{Acknawladgement}

The author is thankful to Mr Khursheed Ahmed for his assistance in computation and to the referes for very valuable suggestions for improvement in the text.

\section{References}

Bhargava B N and Yacob A 1974 Ann. Geophys. 30487

Kane R P 1974 Proc. Indian Acad. Sci. A80 17

Neugebauer M 1976 J. Geophys. Res. 814664

Prigancova A 1978 Geomas. Aeron. 1869

Tarpley J D 1973 J. Atmos. Terr. Phys. 351063

Yacob A and Arcra B R 1974 Ann. Geophys. 30473 